\title{
TINGKAT KEPUASAN PASIEN TERHADAP KUALITAS PELAYANAN OBAT DI INSTALASI FARMASI RUMAH SAKIT ROBERT WOLTER MONGISIDI MANADO
}

\author{
Ni Wayan Mega Juliawati ${ }^{1)}$, Gayatri Citraningtyas ${ }^{1)}$, Imam Jayanto ${ }^{1)}$ \\ ${ }^{1)}$ Program Studi Farmasi FMIPA UNSRAT Manado, 95115
}

\begin{abstract}
Hospitals as service providers are required to be able to provide the best services such as facilities, waiting times for drugs, and counseling to achieve community satisfaction. This study aims to determine the level of patient satisfaction with the quality of drug services at the Pharmacy Installation of Robert Wolter Mongisidi Hospital, Manado. This research is a type of descriptive research with prospective data collection. The number of samples was 383 people. Using research instruments in the from of questionsnaire using the SPSS program. The results obtained by the overall satisfaction index value of -0.33. Satisfaction indexes in each dimension are : tangibles -0.10; empathy -0,21; reliability -0.28; responsiveness -0.5 ; and assurance -0.56 . The conclusion shows that outpatient BPJS patients have not been satisfied with the sevices provided at the Pharmacy Installation of Robert Wolter Mongisidi Hospital, Manado.
\end{abstract}

Keywords : Patient Satisfaction, Service Quality, Outpatient, Robert Wolter Mongisidi Hospital Manado.

\begin{abstract}
ABSTRAK
Rumah sakit selaku penyedia jasa dituntut untuk dapat memberikan pelayanan yang terbaik seperti fasilitas, waktu tunggu obat, dan konseling untuk mencapai kepuasan masyarakat. Penelitian ini bertujuan untuk mengetahui tingkat kepuasan pasien terhadap kualitas pelayanan obat di Instalasi Farmasi Rumah Sakit Robert Wolter Monginsidi Manado. Penelitian ini merupakan jenis penelitian deskriptif dengan pengambilan data secara prospektif. Jumlah sampel sebanyak 383 orang. Proses pengumpulan data dilakukan dengan menggunakan instrumen penelitian dalam bentuk kuisioner. Uji validitas dan reliabilitas kuisioner menggunakan program SPSS. Hasil penelitian diperoleh nilai indeks kepuasan secara keseluruhan sebesar -0,33. Indeks kepuasan pada setiap dimensi berturut-turut antara lain : tangibles $-0,10$; empathy $-0,21$; reliability $-0,28$; responsivenes $-0,5$; dan assurance -0,56. Kesimpulan menunjukan pasien peserta BPJS rawat jalan belum merasa puas terhadap pelayanan yang diberikan di Instalasi Farmasi Rumah Sakit Robert Wolter Mongisidi Manado.
\end{abstract}

Kata Kunci : Apotek, Apoteker, Standar Pelayanan Kefarmasian. 


\section{PENDAHULUAN}

Kualitas pelayanan farmasi rumah sakit merupakan pelayanan farmasi yang menunjuk pada tingkat kesempurnaan pelayanan dalam menimbulkan kepuasan pasien sesuai dengan tingkat kepuasan masyarakat. Kepuasan menjadi bagian penting dalam pelayanan kesehatan sebab kepuasan pasien tidak dapat dipisahkan dari kualitas pelayanan kesehatan (Novaryatiin dkk, 2018). Ada beberapa dimensi yang menjadi tolak ukur bagi pasien dalam melakukan penilaian terhadap pelayanan yang diberikan, antara lain: dimensi berwujud (tangibles), dimensi kehandalan (reliability), dimensi ketanggapan (responsiveness), dimensi jaminan (assurance), dan dimensi empati (empaty) (Isnindar dkk, 2013).

Kepuasan pasien yang dihasilkan baik, berarti pelayanan yang disuguhkan oleh Instalasi Farmasi Rumah Sakit tersebut juga sangat baik. Kepuasan pasien yang dihasilkan tidak baik, berarti perlu dilakukan evaluasi khusus tentang pelayanan Instalasi Farmasi Rumah Sakit yang dilakukan oleh Rumah Sakit tertentu (Novaryatiin dkk, 2018).

Hasil penelitian dari analisis tingkat kepuasan pasien rawat jalan terhadap kualitas pelayanan instalasi farmasi di RSUD Pare menggunakan metode Servqual. Pada kelompok pasien BPJS sebanyak 398 pasien, kualitas pelayanan kefarmasian yang ditinjau dari fasilitas fisik, kehandalan, daya tanggap, jaminan, dan perhatian terhadap pasien peserta
BPJS diperoleh nilai kualitas sebesar 0,4513 dengan interpretasi negatif yang berarti bahwa kualitas pelayanan yang diberikan oleh instalasi farmasi rawat jalan RSUD Pare belum sesuai dengan harapan pasien (Noviana, 2017).

Berdasarkan hasil wawancara sebelumnya terdapat keluhan dari pasien mengenai pelayanan yang diberikan di Instalasi Farmasi di Rumah Sakit Robert Wolter Mongisidi Manado termasuk waktu tunggu pelayanan resep yang terlalu lama. Berdasarkan latar belakang diatas, maka peneliti terdorong untuk melakukan penelitian tentang tingkat kepuasan pasien terhadap pelayanan obat di instalasi farmasi Rumah Sakit Robert Wolter Monginsidi Manado.

\section{METODOLOGI PENELITIAN}

Waktu dan Tempat Penelitian

Penelitian ini dilakukan di Instalasi Farmasi Rumah Sakit Robert Wolter Mongisidi Manado pada bulan April-Agustus 2019.

\section{Jenis Penelitian}

Jenis penelitian ini berupa penelitian deskriptif dengan pengambilan data secara prospektif. Penelitian ini dilakukan terhadap sekumpulan objek yang bertujuan untuk memperoleh informasi tentang tingkat kepuasan pasien terhadap pelayanan obat di instalasi farmasi Rumah Sakit Robert Wolter Mongisidi Manado.

\section{Populasi dan Sampel}

Populasi yang digunakan dalam penelitian ini adalah seluruh pasien peserta 
BPJS rawat jalan yang datang di instalasi farmasi Rumah Sakit Robert Wolter Mongisidi Manado pada bulan Mei-Agustus 2019. Sampel dalam penelitian ini adalah pasien yang datang menerima obat di instalasi farmasi serta memenuhi kriteria selama penelitian berlangsung.

Besarnya sampel berdasarkan rumus Slovin (Sani, 2016).

$$
n=\frac{N}{1+N\left(d^{2}\right)}
$$

Keterangan :

$$
\begin{aligned}
& n=\text { Besar sampel } \\
& N=\text { Populasi } \\
& d=\text { Presisi }(0,05)
\end{aligned}
$$

Diketahui besar populasi penelitian adalah 9000 orang, maka jumlah minimal sampel penelitian adalah 383 orang. Pengambilan data menggunakan kuisioner dan wawancara. Metode yang digunakan adalah uji validitas untuk menunjukan sejauh mana ketepatan dan kecermatan suatu alat ukur dalam melakukan fungsi pengukurannya dan uji reliabilitas menunjukan sejauh mana suatu alat ukur dapat dipercaya.

\section{Analisis Data}

Dalam menganalisis data dalam penelitian ini menggunakan rumus sebagai berikut :

$$
x=\frac{\sum x i}{n} \quad y=\frac{\sum y i}{n}
$$

Keterangan :

$\mathrm{x}=$ skor rata-rata kenyataan/kinerja

$$
\begin{array}{ll}
\mathrm{y} & =\text { skor rata-rata harapan } \\
\sum x i & =\text { Jumlah skor item pernyataan }
\end{array}
$$

kenyataan

$\sum y i=$ Jumlah skor item pernyataan harapan. Analisis yang digunakan untuk menghitung total kualitas pada penelitian ini menggunakan model Weighted Servqual sebagai berikut :

$$
I k j=\sum_{I=0}^{n}(P i j-E i j)
$$

\section{Keterangan:}

$I k j=$ Indeks total kualitas pelayanan

Pij = Performance I pada objek $\mathrm{J}$

Eij = Expectance (harapan atribut pada objek j)

$$
n \quad=\text { Jumlah pernyataan }
$$

Berdasarkan hasil dari indeks total kualitas pelayanan dapat diartikan bahwa :

1. Indeks nol

Kondisi yang menyatakan bahwa harapan pelanggan tepat sama dengan kinerja yang dihasilkan oleh perusahaan.

2. Indeks negatif

Kondisi yang menyatakan bahwa harapan pelanggan lebih besar dari kinerja aktual yang dihasilkan perusahaan, keadaan ini meyebabkan kualitas pelayanan menjadi tidak sesuai dengan harapan pelanggan.

\section{Indeks positif}

Kondisi yang menyatakan bahwa harapan pelanggan mengenai pelayanan lebih kecil dari kinerja yang diberikan dan dampaknya adalah kulitas pelayanan yang ideal menurut pelanggan (Priyatno, 2010). 


\section{HASIL DAN PEMBAHASAN}

Karakteristik Pasien BPJS Rawat Jalan di Instalasi Farmasi Rumah Sakit Robert Wolter Mongisidi Manado

Tabel 1. Karakteristik Pasien BPJS Rawat Jalan di Instalasi Farmasi Rumah Sakit Robert Wolter Mongisidi Manado

\begin{tabular}{lcc}
\hline \multirow{2}{*}{ Karateristik } & \multicolumn{2}{c}{ Total } \\
\cline { 2 - 3 } & $\mathbf{N}$ & $\mathbf{( \% )}$ \\
\hline Jenis Kelamin & & \\
Laki-laki & 158 & 41,3 \\
Perempuan & 225 & 58,7 \\
\hline Usia (Depkes, 2009) & & \\
$(17-25$ tahun) & 19 & 4,9 \\
$(26-35$ tahun) & 81 & 21,1 \\
$(36-45$ tahun) & 102 & 26,6 \\
$(46-55$ tahun) & 94 & 24,5 \\
$(56-65$ tahun) & 65 & 16,9 \\
$(>65$ tahun) & 22 & 5,7 \\
\hline
\end{tabular}

\section{Pendidikan \\ Terakhir}

$\begin{array}{lll}\text { SD/Sederajat } & 30 & 7,8\end{array}$

SMP/Sederajat $\quad 50 \quad 13,1$

SMA/Sederajat $\quad 235 \quad 61,4$

Perguruan Tinggi $68 \quad 17,7$

\section{Jenis Pekerjaan}

Tidak 147

bekerja/IRT

Wiraswasta

88

Buruh/Karyawan

Petani

Pengajar

PNS

Lainnya

Hasil penelitian menunjukan responden

terbanyak berjenis kelamin perempuan yakni 225 pasien $(58,7 \%)$, dan jenis kelamin laki-laki sebanyak 158 pasien (41,3\%). Dari hasil penelitian yang menunjukan jenis kelamin tidak ada hubungan yang signifikan dengan kepuasan pasien.

Karakteristik usia pasien pada penelitian ini menunjukkan pasien peserta BPJS rawat jalan yang menerima pelayanan obat di Instalasi Farmasi Rumah Sakit Robert Wolter Mongisidi Manadopada kelompok usia 36-45 tahun sebanyak 102 pasien $(26,6 \%)$ (Tabel 1).

Hasil penelitian menunjukan banyak ditemukan pekerjaan tidak bekerja/IRT yaitu sebanyak 147 pasien $(38,4 \%)$. Penelitian ini menunjukan bahwa pekerjaan dapat mempengaruhi tingkat kepuasan pasien dimana pekerjaan dapat mempengaruhi komunitas dimana mereka bergaul mendapatkan informasi tambahan tentang pelayanan kesehatan yang seharusnya mereka dapatkan.

Karakteristik pasien berdasarkan pendidikan terakhir menunjukan bahwa yang paling banyak ditemukan pada pendidikan SMA sebanyak 235 pasien $(61,4 \%)$. Hal ini sesuai dengan tingkat pendidikan yang semakin tinggi akan berpengaruh terhadap pengetahuan, daya tangkap, informasi, sikap dan minat terhadap suatu pilihan. 
PHARMACON- PROGRAM STUDI FARMASI, FMIPA, UNIVERSITAS SAM RATULANGI, Volume 8 Nomor 4 November 2019

Analisis Tingkat Kepuasan Pasien BPJS Rawat Jalan Terhadap Kualitas Pelayanan Obat di Instalasi Farmasi Rumah Sakit Robert Wolter Mongisidi Manado Secara Keseluruhan.

Tabel 2. Perhitungan dan Penilaian Tingkat Kepuasan Pasien BPJS Rawat Jalan Pada Setiap Item

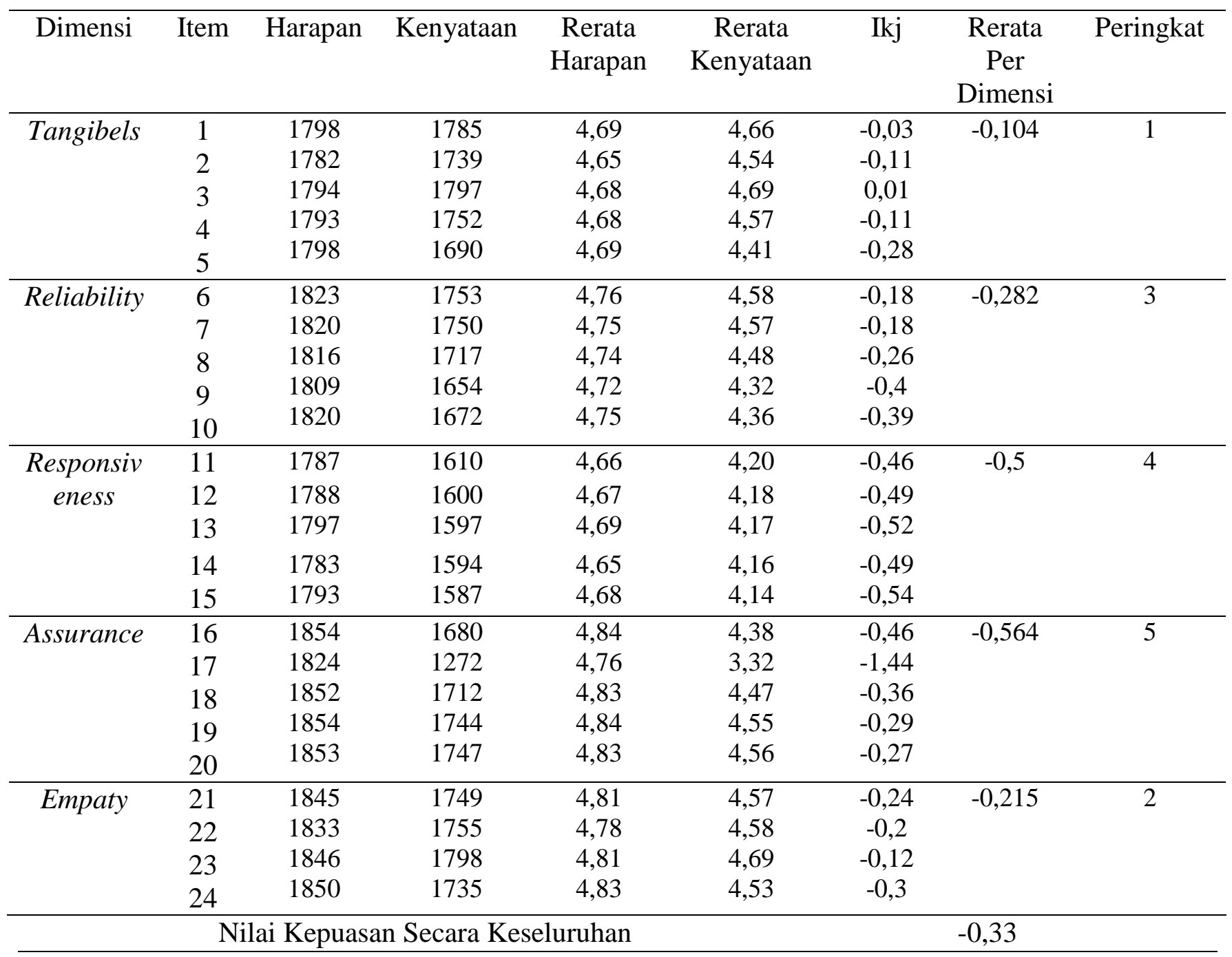


PHARMACON- PROGRAM STUDI FARMASI, FMIPA, UNIVERSITAS SAM RATULANGI,

Volume 8 Nomor 4 November 2019

a. Gambaran Kepuasan Pasien BPJS Rawat Jalan Berdasarkan Dimensi Tangibles

Kuisioner pada dimensi tangibles diwakili oleh lima butir pernyataan. Kepuasan pasien dilihat dari dimensi tangibels secara keseluruhan belum memuaskan pasien. Terlihat pada Tabel 2, nilai indeks total kualitas pelayanan terendah pada angka $(-0,28)$ yang terletak pada item 5 dan nilai indeks total kualitas pelayanan tertinggi pada angka $(0,01)$.

Secara keseluruhan, pasien belum puas dilihat dari dimensi berwujud (Tangibles) karena nilai rerata dimensi yaitu $-0,104$. Berdasarkan analisa, seharusnya item 2 dan 5 lebih diperhatikan oleh pihak rumah sakit untuk melengkapi fasilitas yang memadai dan mendukung di Instalasi Farmasi seperti disediakannya media baca untuk mengisi waktu luang pasien, begitu juga dengan fasilitas tempat duduk sehingga membuat kenyamanan pasien saat mengantri obat.

\section{b. Gambaran Kepuasan Pasien BPJS} Rawat Jalan Berdasarkan Dimensi Reliability

Kuisioner pada dimensi reliability diwakili oleh lima butir pernyataan, berdasarkan Tabel 2, dapat diketahui nilai Ikj terendah berada pada item 9 dengan angka $(-0,4)$ dan nilai Ikj tertinggi pada item 10 dengan angka $(-0,39)$. Secara keseluruhan dimensi reliability menunjukan angka $-0,28$ yang berarti pasien belum puas. Hal itu disebabkan karena banyaknya pasien yang mengantri sehingga petugas di Instalasi tidak menjelaskan tentang efek samping obat yang diberikan kepada pasien. Sesuai dengan Permenkes nomor 72 tahun 2016, beban kerja apoteker di Instalasi Farmasi Rumah Sakit yaitu rasio 1 apoteker untuk 50 pasien rawat jalan. Dilihat pada jumlah apoteker yang bertugas di Instalasi Farmasi Rumah Sakit Robert Wolter Mongisidi Manado terdiri dari 3 orang apoteker, yang tidak sesuai dengan standar, kenyataan pelayanan obat dengan jumlah apoteker yang memberikan pelayanan sedikit sedangkan pasien banyak yang mengantri, seharusnya pihak rumah sakit ini menambah jumlah apoteker.

\section{c. Gambaran Kepuasan Pasien BPJS Rawat Jalan Berdasarkan Dimensi Responsiveness}

Kuisioner pada dimensi responsiveness (ketanggapan) diwakili oleh 5 butir pernyataan. Diketahui nilai Ikj terendah pada item 15 yang berisi tentang obat diberikan tepat waktu oleh petugas farmasi dengan angka $(-0,54)$ dan nilai Ikj tertinggi pada item 11 yang berisi petugas di instalasi farmasi cepat tanggap dalam menangani keluhan pasien dengan angka ($0,46)$. Secara keseluruhan pasien belum puas dengan dimensi ketanggapan dilihat Ikj yang rerata dimensi yaitu $-0,5$.

Pasien belum merasa puas pada dimensi ini karena pasien BPJS rawat jalan merasa petugas kesehatan belum tanggap dalam melayani kebutuhan pasien seperti petugas tidak memberikan obat tepat waktu. Oleh karena itu pihak apoteker di Instalasi Farmasi Rumah Sakit lebih sigap dalam pelayanan agar waktu bisa lebih cepat. Kepuasan terhadap daya tanggap mengandung faktor komunikasi dan situasi fisik di sekeliling pelanggan. Komunikasi 
PHARMACON- PROGRAM STUDI FARMASI, FMIPA, UNIVERSITAS SAM RATULANGI, Volume 8 Nomor 4 November 2019

kepada pelanggan membentuk persepsi yang lebih positif. Pelayanan yang cepat tanggap, memiliki kesigapan dan ketulusan dalam menjawab pertanyaan atau permintaan pelanggan (Tulumang dkk, 2015).

\section{d. Gambaran Kepuasan Pasien BPJS Rawat Jalan Berdasarkan Dimensi Assurance}

Dimensi assurance (jaminan) merupakan tolak ukur kemampuan serta penegetahuan petugas agar sepenuhnya dapat dipercaya tanpa ragu sebagai profesionalisme yang handal. Kuisioner pada dimensi ini diwakili oleh lima butir pernyataan.

Nilai Ikj terendah terletak pada item 17 dengan angka $(-1,44)$ dan nilai Ikj tertinggi terletak pada item 20 dengan angka $(-0,27)$. Secara keseluruhan nilai rata-rata Ikj sebesar -0,56. Nilai ini memberikan gambaran pasien tidak puas akan kinerja di Instalasi farmasi dari segi dimensi jaminan.

Pasien belum puas pada dimensi ini karena pada kenyataan apoteker tidak memberikan konseling pada pasien, hal ini bisa dipengaruhi oleh banyaknya pasien yang mengantri padahal ruang konseling sudah tersedia. Pihak rumah sakit menambah jumlah apoteker serta melakukan pelatihan konseling pada apoteker agar bisa diterapkan di rumah sakit tersebut. Menurut Isnindar dkk (2013), penelitian yang dilakukan di Instalasi Farmasi RSUD Dr Soedarso Pontianak pada dimensi jaminan memiliki nilai Ikj terendah dari dimensi lainnya, karena pasien merasa tidak pernah melakukan konseling di Instalasi Farmasi padahal ruang konsultasi sudah tersedia pada Instalasi tersebut.

\section{e. Gambaran Kepuasan Pasien BPJS Rawat Jalan Berdasarkan Dimensi Empathy}

Kuisioner pada dimensi empathy di wakili oleh 4 pernyataan, nilai Ikj terendah pada terletak pada item 21 dengan angka ($0,24)$ dan nilai Ikj tertinggi terletak pada item 22 dengan angka (-0,2). Secara keseluruhan pasien belum puas dengan dimensi empati yang diberikan rumah sakit, ini terlihat dengan nilai Ikj yang menunjukan nilai negatif dengan nilai rerata perdimensi yaitu -0,21. Hal ini disebabkan karena dilihat dari kenyataan masih banyak apoteker dan petugas di instalasi mengutamakan melayani pasien dari kalangan tentara dan keluarga tentara dari pada pasien umum sehingga banyak pasien umum akan antri lebih lama dari pada pasien tentara.

Berdasarkan nilai indeks total
kepuasan pasien masing- masing menunjukkan nilai negatif, ini menunjukkan kenyataannya masih ada ketidaksesuaian yang dirasakan pasien yang masih menuntut petugas di Instalasi Farmasi untuk memberikan pelayanan yang mengedepankan perhatian secara pribadi kepada pasien. Sebagaimana dengan penelitian Isnandar., dkk (2013), yang mendapatkan nilai indeks total kepuasan pasien pada dimensi ini berada pada nilai negatif, menyatakan perlunya pelatihan dalam hal keterampilan antar pribadi/petugas khususnya menyangkut interaksi dengan pasien dan mengembangkan metode rekrutmen dan referensi inovatif untuk menarik karyawan terbaik, maka secara tidak langsung pasien 
PHARMACON- PROGRAM STUDI FARMASI, FMIPA, UNIVERSITAS SAM RATULANGI, Volume 8 Nomor 4 November 2019

akan menjadi antusias dan patuh dalam menjalankan terapi.

\section{KESIMPULAN}

Tingkat kepuasan pasien terhadap pelayanan yang diberikan di Instalasi Farmasi Rumah Sakit Robert Wolter Mongisidi Manado berdasarkan nilai kepuasan secara keseluruhan $(-0,33)$ yang berarti pasien belum merasa puas terhadap pelayanan yang diberikan di Instalasi Farmasi Rumah sakit Robert Wolter Mongisidi.

\section{SARAN}

Perlu adanya perbaikan di Instalasi Farmasi Rumah Sakit khususnya pelayanan dari segi dimensi jaminan, perlu menambahkan apoteker untuk memberikan konseling kepada pasien, penambahan kursi diruang tunggu, petugas perlu memberikan informasi tentang efek samping obat.

\section{DAFTAR PUSTAKA}

Isnindar, S. I., Robiyanto. 2013. Analisis Tingkat Kepuasan Pasien Rawat Inap di Ruangan Penyakit Dalam Terhadap Pelayanan di Instalasi Farmasi Rumah Sakit Periode
Desember 2011- Februari 2012. Jurnal Manajemen dan Pelayanan Farmasi. 3(4): 231-248.

Novaryatiin, S., Ardhany, S. D., Aliyah, S. 2018. Tingkat Kepuasan Pasien Terhadap Pelayanan Kefarmasian di RSUD Dr. Murjani Sampit. Journal of Pharmacy. 1(1): 22-26.

Noviana, P. 2017. Analisis Tingkat Kepuasan Pasien Rawat Jalan Terhadap Kualitas Pelayanan Instalasi Farmasi di RSUD Pare Menggunakan Metode Servqual. Jurnal Wiyata. 4(2): 111-120.

Priyatno, D. 2010. Paham Analisa Statistik Data dengan SPSS, (Cetakan ke1). Mediakom, Yogyakarta.

Sani, F. 2016. Metodologi Penelitian Farmasi Komunitas dan Eksperimental Edisi 1 Cetak 1. Deepublish, Yogyakarta.

Tulumang, J. S.,Kandou, D. G. 2015. Tingkat Kepuasan Pasien atas Pelayanan Rawat Jalan di Poli Penyakit Dalam (Interna) di RSU Prof. R. D. Kandou MalalayangManado. Universitas Sam Ratulangi Manado. Artikel Penelitian. 5(2): 546-556. 